\title{
Field Spectroscopy as a Tool for Enhancing Water Quality Monitoring in the ACE Basin, SC
}

\author{
Caitlyn C. Mayer ${ }^{1}$ and Khalid A. Ali ${ }^{2}$
}

AUTHORS: ${ }^{1,2}$, Adjunct Professor, Department of Geology and Environmental Geosciences, College of Charleston, Charleston, SC 29424. ${ }^{2}$ Assistant Professor, Department of Geology and Environmental Geosciences, College of Charleston, Charleston, SC 29424. REFERENCE: Proceedings of the 2016 South Carolina Water Resources Conference, held October 12-13, 2016 at the Columbia Metropolitan Convention Center.

\begin{abstract}
The Ashepoo, Combahee, Edisto (ACE) Basin in South Carolina is one of the largest undeveloped estuaries in the Southeastern United States. This system is monitored and protected by several government agencies to ensure its health and preservation. However, as populations in surrounding cities rapidly expand and land is urbanized, the surrounding water systems may decline from an influx of contaminants, leading to hypoxia, fish kills, and eutrophication. Conventional in situ water quality monitoring methods are timely and costly. Satellite remote sensing methods are used globally to monitor water systems and can produce an instantaneous synopsis of color-producing agents (CPAs), including chlorophyll- $a$, suspended matter (TSM), and colored-dissolved organic matter by applying bio-optical models. In this study, field, laboratory, and historical land use land cover (LULC) data were collected during the summers of 2002, 2011,2015, and 2016. The results indicated higher levels of chlorophyll, ranging from 2.94 to $12.19 \mu \mathrm{g} / \mathrm{L}$, and TSM values were from 60.4 to $155.2 \mathrm{mg} / \mathrm{L}$ between field seasons, with values increasing with time. A model was developed using multivariate, partial least squares regression (PLSR) to identify wavelengths that are more sensitive to chlorophyll $-a\left(\mathrm{R}^{2}=0.49\right.$; RMSE $\left.=1.8 \mu \mathrm{g} / \mathrm{L}\right)$ and TSM $\left(\mathrm{R}^{2}=0.40\right.$; $\mathrm{RMSE}=$ $12.9 \mathrm{mg} / \mathrm{L}$ ). The imbrication of absorption and reflectance features characterizing sediments and algal species in ACE Basin waters make it difficult for remote sensors to distinguish variations among in situ concentrations. The results from this study provide a strong foundation for the future of water quality monitoring and for the protection of biodiversity in the ACE basin.
\end{abstract}

\section{INTRODUCTION}

Coastal watersheds are essential components of the hydrologic cycle, as these are the regions where all the water from the surface and the ground converge into a single area and drain into the ocean (USEPA 2012). Since these geographic regions consist of a variety of water sources, they are an essential focus of study for managing and monitoring coastal resources in South Carolina. Coastal watersheds begin with the headwaters of rivers and streams, including adjacent wetlands, and as the water drains toward the coast, it is influenced by a variety of land and water uses (i.e., agricultural and industrial operations and urban development). As these waters reach coastal areas, the rivers empty into estuaries, along with any nutrient-enriched runoff from the different lands it passes through, before discharging into the ocean.

The Southeastern United States is one of the fastest growing populations nationwide, with the state of South Carolina experiencing some of the fastest rates of urbanization
(7.24 \% per year), which exceed the average U.S population growth rate (Allen and $\mathrm{Lu}$ 2003). To accommodate this growth, land is urbanized, which is one of the major causes of coastal wetland and estuarine loss. Urbanization also influences the hydrological and geological dynamics of coastal systems by causing concentrated flows of nutrients and chemical pollutants to flow into estuaries during flood events (storm water runoff), while non-flood events receive diffused discharge into groundwater (Lee et al., 2006). Urbanization changes land from permeable forest or wetlands to impermeable surfaces, such as parking lots, roads, buildings, and rooftops (Leopold, 1968). The increase in impervious areas in a catchment changes the natural hydrogeological regime of a system and results in concentrated areas of rain runoff (Lee et al., 2006). This can lead to the deterioration of water quality, as coastal systems near urban areas interact with nutrient pollution that would normally have been buffered through pervious surfaces (Bannerman et al., 1993). 
It is generally recognized that increased levels of nutrient pollution increase eutrophication (nutrient enrichment to waters), which can lead to an abundance of chlorophyll- $a$ (Chl-a) in the water (from algal blooms) (Anderson et al., 2002). Natural estuarine eutrophication is usually a slow process that stimulates algal growth, resulting in productive ecosystems (Bricker et al., 1999). However, in recent decades, anthropogenic activities have accelerated nutrient input into estuarine systems, and research has shown that more coastal algal blooms have occurred than in past decades (Gilbert et al., 2005). Agriculture is one of these activities, contributing large concentrations of carbon, nitrogen, and phosphorous into estuaries via colored dissolved organic matter (CDOM), especially after it rains. CDOM is the largest source of organic carbon in the aquatic environment, contributing to light absorption and bacterial respiration in estuarine systems. It can transport large concentrations of nutrients to estuaries, which can indirectly promote algal growth (Corbert, 2007). Agriculture, along with urban development, can also cause soil erosion. When eroded soil enters the water system, the concentration of total suspended matter (TSM) increases. TSM are particles in water that cannot pass through a $0.7 \mu \mathrm{m}$ glass fiber filter, including inorganic sediments and organic particles (phytoplankton). Suspended matter can affect aquatic habitats as they absorb heat from the sun, increase the water temperature, and consequently lower the available concentrations of dissolved oxygen necessary for aquatic life (Etheridge et al., 2015).

To assess the health of coastal watersheds, water quality can be used as a key index to evaluate the stressors posed on the environment. Obtaining water quality measurements using conventional methods is labor intensive, costly, and time consuming, and they lack spatial and temporal resolution, making it difficult to monitor water quality dynamics in real time. In response to increasing terrestrially derived constituents from agriculture and urbanization, coastal watersheds, especially in South Carolina, may potentially be exposed to higher fluxes of sediments and nutrients. Therefore, it is imperative to seek more robust methods of monitoring coastal systems.

Remote sensing methods are used globally to monitor water systems and can produce an instantaneous synopsis of the water quality (McClain, 2009). Remote sensing operates by measuring the quantity and type of electromagnetic radiation (EMR) exiting the water; which is a function of the various color-producing agents (CPAs) present in the water column. The universality of satellite-based remote sensing data has assisted in the efforts to identify CPAs, which are materials in the water that can change water color (reflectance) and affect water quality. The three primary CPAs in coastal watersheds are (1) Chl- $a$, a primary pigment found in all phytoplankton species; (2) TSM, consisting of minerals, sediments, and organic particle such as decomposing phytoplankton and zooplankton; and (3) CDOM from decaying organic matter that can cause yellow color alterations in the water body.

The convoluted interactions of these CPAs have been extensively studied in ocean systems (e.g., Ryan et al., 2016; Yacobi et al., 2011; Gitelson et al., 2008; Schalles, 2006), and as Chl- $a$ is prevalent in photosynthetic organisms, estimating these concentrations and understanding the interactions with other CPAs is essential for the remote sensing of water quality (Schalles, 2006). Remote sensing methods measure water quality by correlating co-located satellitederived or field-derived reflectance with in situ samples of CPAs. Conventional satellite technology uses multispectral sensors to monitor the water quality at moderate to high spatial and temporal resolutions. These sensors can predict the concentrations of Chl- $a$ in ocean waters (Klemas, 2011) through the use of global algorithms that relate spectral reflectance features in the blue and green portion of the spectrum to Chl- $a$ concentration. However, these algorithms are broadly calibrated (IOCCG, 2000; McClain, 2009) and are limited to waters that are dominated by Chl- $a$, thus resulting in low accuracy model predictions in ACE type waters that possess multiple CPAs.

To model the varying CPAs found in turbid coastal waters, empirical remote sensing algorithms that employ reflectance values in the near-infrared (NIR) regions of the EMR have been found to be successful for modeling Chl- $a$, as a limited amount of absorption by suspended solids and CDOM is observed in these regions of EMR (Doxaran et al., 2002; Robertson et al., 2009; Moses et al., 2012). Empirical models using ratios of bandwidths are found by rationing spectral bands that display reflectance and absorption features due to phytoplankton:

$$
\text { (1) } \mathrm{R}=\left(\frac{R_{R S}\left(\lambda_{1}\right)}{R_{R S}\left(\lambda_{2}\right)}\right)
$$

where $R_{R S}(\lambda)$ represents a specific band (wavelength) within a sensor dataset. The reflectance $(\mathrm{R})$ value derived from the ratio can then be correlated to known concentrations of in situ CPAs that were collected within the same spatial and temporal constraints as the satellite image (Witter et al., 2009). From this band ratio, the specific wavelengths where Chl- $a$ absorption features are observed can be used to calibrate the equation and is represented by

$$
\text { (2) }[\text { Chl-a }] \propto=\frac{R_{R S}\left(\lambda_{N I R}\right)}{R_{R S}\left(\lambda_{\text {Red }}\right)} \text {, }
$$

where $\lambda_{N I R}$ is the Chl- $a$ maximum reflectance peak near $700 \mathrm{~nm}$ due to decreasing Chl- $a$ absorption and increasing absorption by water, and $\lambda_{\text {Red }}$ is the absorption maximum around $670 \mathrm{~nm}$ due to increasing Chl- $a$ absorption (Vasilikov and Kopelevich, 1982; Gitelson, 1992; Han, 1997; Moses et al., 2012). Spectral features may vary depending upon the 
concentration and type of Chl- $a$, as well as the resolution of the satellite sensor. These ratio models have produced accurate estimates of Chl-a concentration in coastal watersheds and turbid estuarine environments around the world (Gurlin et al., 2011; Moses et al., 2012). A summary of six published band-ratio algorithms that utilize blue/green and red/near-infrared spectral regions is detailed in Table 1. The development of these models was examined briefly as an implication to the applicability of the PLSR method when adapted to the in situ reflectance dataset.

Hyperspectral sensors collect reflectance signals across the EMR using many narrow bands (with high spectral resolution), which enhances the retrieval of Chl- $a$ signals in optically complex waters. With consecutive narrow bands, hyperspectral sensors are capable of quantifying reflectance values regardless of any shift in crucial spectral features due to the presence of multiple CPAs (Ryan et al., 2016). These sensors can be field based or secured on spaceborne and airborne platforms, resulting in high spectral and spatial resolution. In situ hyperspectral measurements have previously been used to calibrate algorithms for smaller water bodies, such as estuarine sites, specifically studies in the Altamaha and St.
Mary's River, Georgia and Long Bay, South Carolina, which resulted in the development of successful regression models $\left(\mathrm{R}^{2}=0.88, \mathrm{R}^{2}=0.72, \mathrm{R}^{2}=0.80\right)$ that showed correlations with Chl- $a$ and successful applications for estimating CPAs in estuarine surface waters (Bhatti et al., 2010; Ryan et al., 2016).

\section{MULTIVARIATE APPROACHES:}

As advances in technology lead to the availability and accessibility of hyperspectral(continuous bandwidths) remote sensors, approaches that can address the multidimensionality and collinearity of large, higher resolution satellite datasets must be applied. Factor analysis approaches, which consider what factors influence the data the most, involve a varimaxrotated method of principal component analysis (VPCA) and regression model methods, such as PLSR. These methods can reduce the dimensionality of large datasets and allow the end user to identify potentially correlated variables.

VPCA identifies the least number of linear combinations of the available variables that summarize the data without compromising its variability (Maitra and Yan, 2008). This variance is exemplified by several primary orthogonal components with scores that help define the specific

Table 1. Band ratio algorithms used to estimate chlorophyll-a concentrations $(C)$ from remote sensing reflectance $\left(R_{R S}\right)$ in the $A C E$ Basin. Validation parameters were determined using the r-squared value $\left(R^{2}\right)$ and root-mean-square error (RMSE) in micrograms per liter $(\mu \mathrm{g} / \mathrm{L})$ of the predicted versus actual Chl-a concentrations.

\begin{tabular}{|c|c|c|c|}
\hline Algorithm & Algorithm Equation & Reference & $\begin{array}{l}\text { Validation Parameters } \\
(\mu \mathrm{g} / \mathrm{L})\end{array}$ \\
\hline \multicolumn{4}{|l|}{ Blue Green Models } \\
\hline Morel-1 & $\begin{array}{l}\mathrm{R}=\log (\mathrm{R} 443 / \mathrm{R} 555) \\
\mathrm{C}=10^{\wedge}(0.2492-1.768 \mathrm{R})\end{array}$ & $\begin{array}{l}\text { O’Reilly et al. } \\
\text { (1998) }\end{array}$ & $\begin{array}{l}\mathrm{R}^{2}=0.0026 \\
\mathrm{RMSE}=9.92\end{array}$ \\
\hline Morel-3 & $\begin{array}{l}\mathrm{R}=\log (\mathrm{R} 490 / \mathrm{R} 555) \\
\mathrm{C}=10^{\wedge}\left(0.20766-1.82878 \mathrm{R}+0.75885 \mathrm{R}^{2} 0.73979 \mathrm{R}^{3}\right)\end{array}$ & $\begin{array}{l}\text { O’Reilly et al. } \\
\text { (1998) }\end{array}$ & $\begin{aligned} \mathrm{R}^{2} & =0.0096 \\
\mathrm{RMSE} & =10.04\end{aligned}$ \\
\hline OC4v4 & $\begin{array}{l}\mathrm{R}=\log (\max [\mathrm{R} 443, \mathrm{R} 450, \mathrm{R} 510] / \mathrm{R} 555) \\
\mathrm{C}=10^{\wedge}\left(0.366-3.067 \mathrm{R}+1.930 \mathrm{R}^{2}+0.649 \mathrm{R}^{3}-1.532 \mathrm{R}^{4}\right)\end{array}$ & $\begin{array}{l}\text { O’Reilly et al. } \\
\text { (1998) }\end{array}$ & $\begin{array}{l}\mathrm{R}^{2}=0.0021 \\
\mathrm{RMSE}=2.83\end{array}$ \\
\hline $\begin{array}{l}{ }^{\star} \text { Adapted Morel-1 } \\
\text { Model }\end{array}$ & $\begin{array}{l}\mathrm{R}=\log (\mathrm{R} 443 / \mathrm{R} 570) \\
\mathrm{C}=10^{\wedge}(0.2492-1.768 \mathrm{R})\end{array}$ & & $\begin{aligned} \mathrm{R}^{2} & =0.0082 \\
\mathrm{RMSE} & =3.71\end{aligned}$ \\
\hline $\begin{array}{l}{ }^{*} \text { Adapted Morel-3 } \\
\text { Model }\end{array}$ & $\begin{array}{l}\mathrm{R}=\log (\mathrm{R} 443 / \mathrm{R} 560) \\
\mathrm{C}=10^{\wedge}\left(0.20766-1.82878 \mathrm{R}+0.75885 \mathrm{R}^{2}-0.73979 \mathrm{R}^{3}\right)\end{array}$ & & $\begin{array}{c}\mathrm{R}^{2}=0.012 \\
\mathrm{RMSE}=3.74\end{array}$ \\
\hline $\begin{array}{l}{ }^{*} \text { Adapted OC4v4 } \\
\text { Model }\end{array}$ & $\begin{array}{l}R=\log (\max [R 440, R 450, R 510] / R 580) \\
C=10^{\wedge}\left(0.0162-9.372 R-25.55 R^{2}+0.649 R^{3}-1.532 R^{4}\right)\end{array}$ & & $\begin{array}{c}\mathrm{R}^{2}=0.148 \\
\mathrm{RMSE}=2.22\end{array}$ \\
\hline \multicolumn{4}{|c|}{ Red-Near Infrared Models } \\
\hline 2-Band MODIS & $\begin{array}{l}\mathrm{R}=\mathrm{R}^{-1}(667)^{\star} \mathrm{R}(748) \\
\left.\mathrm{C}=0.7843-0.1573 \mathrm{R}+0.0319 \mathrm{R}^{2}\right)\end{array}$ & $\begin{array}{l}\text { Yacobi et al. } \\
\text { (2011) }\end{array}$ & $\begin{array}{l}\mathrm{R}^{2}=0.0028 \\
\mathrm{RMSE}=6.36\end{array}$ \\
\hline 3-Band MERIS & $\begin{array}{l}\mathrm{R}=\mathrm{R}^{-1}(665)-\mathrm{R}-1(708)^{\star} \mathrm{R}(753) \\
\mathrm{C}=-0.1305-0.011 \mathrm{R}+0.0088 \mathrm{R}^{2}\end{array}$ & $\begin{array}{l}\text { Yacobi et al. } \\
(2011)\end{array}$ & $\begin{array}{l}\mathrm{R}^{2}=0.0028 \\
\mathrm{RMSE}=6.36\end{array}$ \\
\hline \multicolumn{4}{|c|}{ Red-NIR and Blue Green Models } \\
\hline Hladik & $\begin{array}{l}\mathrm{R}=(\text { aveR650 + R700) }-\mathrm{R} 675 /(\text { aveR } 440+\mathrm{R} 550) \\
\mathrm{C}=3.72+34.92 \mathrm{R}+67.63 \mathrm{R}^{2}\end{array}$ & Hladik (2004) & $\begin{array}{l}\mathrm{R}^{2}=0.096 \\
\mathrm{RMSE}=6.70\end{array}$ \\
\hline $\begin{array}{l}\text { * Adapted Hladik } \\
\text { Model }\end{array}$ & $\begin{array}{l}R=(\text { aveR650 + R700 })-R 675 /(\text { aveR } 440+R 550) \\
C=5.811+20.39 R-49.81 R^{2}\end{array}$ & & $\begin{array}{c}\mathrm{R}^{2}=0.0991 \\
\mathrm{RMSE}=2.33\end{array}$ \\
\hline
\end{tabular}


wavelengths responsible for characterizing water quality parameters (Fu et al., 2013). VPCA was selected as an applicable multivariate statistical approach for its ability to decrease the dimensionality of the data, eliminate collinearity among the data, and transform large datasets into smaller datasets of unrelated indices. This approach has been applied successfully in previous ocean color modeling research studies, where strong correlation models for Chl- $a$ prediction were produced (Sathyendranath et al., 1994; Gao et al., 2000; Gross-Colzy et al., 2007; Ortiz et al., 2013; Ali et al., 2013; Ryan et al., 2016).

PLSR was developed in the 1980s by Herman Wold and has since gained acceptance in its use for spectral analysis. Like VPCA, this approach extracts the least number of eigenvectors from the explanatory variables (Ortiz et al., 2013) but expands the statistics further by incorporating a response variable during the extraction and performing a least-squares regression on the components instead of the original data, which provides correlations specific to the observed data.

This technique is more biased than the VPCA approach because it is suited to the observational data, and because of that, it has been employed in several successful remote sensing studies (Ryan et al., 2016; Ali et al., 2013; Robertson et al., 2009). Modeling using PLSR assumes that observations of reflectance are directed by factors that are linear combinations of explanatory variables (Roberston et al., 2009). The vector loadings (P) of the spectra are approximated by a matrix consisting of explanatory variables (X) and the response variables (Y) (i.e., CPAs). The result is then normalized over a length of 1 , and the reflectance data, $\mathrm{X}$, and first loading vector, $\mathrm{P}$, are used to estimate the first column of the regression factor matrix, T (Eq. 3). The process of multiple linear regressions determines the vector loadings of the CPAs, Q, and computes their residuals, F (Eq. 4). Using these residuals, these calculations are replicated for the second regression factor and so on, with $\mathrm{F}$ and $\mathrm{E}$ representing the error matrices that are accepted as independent. The goal of PLSR modeling is to decrease the normalization of F while maximizing the covariance between $\mathrm{X}$ and $\mathrm{Y}$. The general model of multivariate PLSR is described as follows:

$$
\begin{aligned}
& \text { (3) } X=T P^{T}+E \\
& \text { (4) } Y=U Q^{T}+F
\end{aligned}
$$

PLSR was chosen for this study because of its ability to recognize significant relationships between $\mathrm{X}$ and $\mathrm{Y}$ variables. The Ashepoo Combahee Edisto (ACE) Basin is one of the largest undeveloped estuaries in the nation, with a variety of optical properties, draining approximately $8,000 \mathrm{~km}^{2}$ into the Atlantic Ocean (Nobel et al., 2003) and is part of the National Estuarine Research Reserve System (NERRS; a partnership between NOAA and coastal states, to protect and monitor 28 different estuaries). The models developed from this study were used to retrieve water quality data at higher spatial and temporal resolution. This will enhance monitoring methods in South Carolina and may be used by water managers and coastal resource managers to respond to environmental concerns more efficiently.

Prior to this study, no remote sensing-based models of the biogeochemical processes for the ACE Basin NERRs had been developed. To accurately characterize the local biogeochemical, spectral, and temporal dynamics of this coastal environment, regionally tiered algorithms were developed using empirical and multivariate approaches with in situ water samples and multispectral and hyperspectral reflectance data. The goal of this study was to develop models that could accurately assess the water quality of a coastal watershed by determining the visible infrared (VIR) signatures of select CPAs and to establish a historical comparison of the relationships between urbanization and water quality over time.

\section{STUDY AREA}

St. Helena Sound estuary, along the coast of South Carolina between Edisto Island and Hunting Island (Figure 1), is a

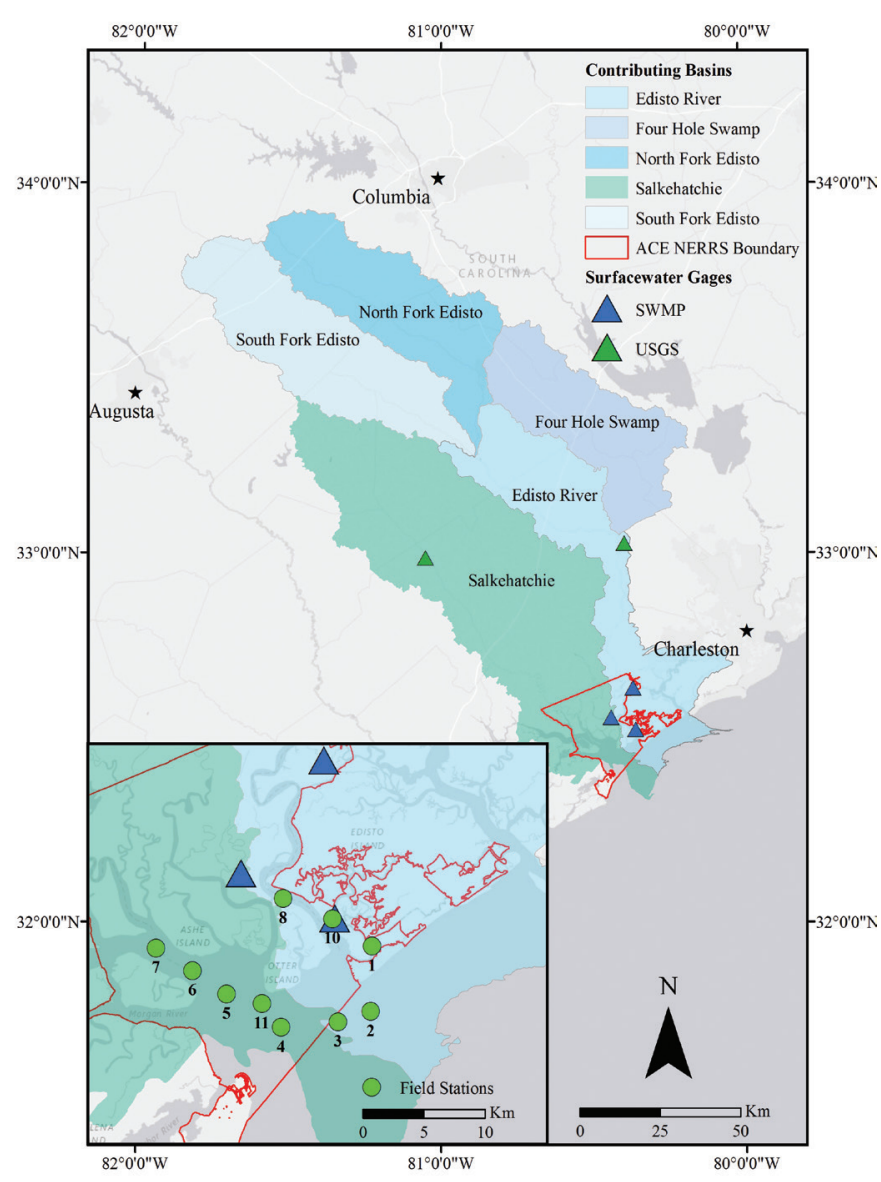

Figure 1. Map of ACE Basin. Salkehatchie (left) and Edisto (right) 6-digit HUCs overlaid with USGS gauges (dark green triangles) and SWMP gauges (dark blue triangles). Inset shows field stations in St. Helena Sound (neon green circles), Coastal South Carolina U.S.A. 
drowned river valley that likely formed during the Pleistocene and was flooded during a high sea level stage (Cooke, 1936; Bearden et al., 1985). Historical weather data indicate that the ACE Basin has a subtropical climate, with average water temperatures of $20{ }^{\circ} \mathrm{C}$ and average annual precipitation of 2.8 $\mathrm{cm}$ from June 2015 to September 2016 (NOAA, 2015b). This coastal portion of the ACE Basin is characterized by marsh islands, barrier islands, and tidal creeks (Mathews et al., 1980; Bearden et al., 1985) with elevations ranging from 0.5 to 12 $\mathrm{m}$ and inland sub-basins ranging from 12 to $214 \mathrm{~m}$. All the surface water from the ACE Basin discharges into the Atlantic Ocean via St. Helena Sound (SCWRC 1972), and this area has an extensive set of LULC data as well as gauging stations for both water quality and quantity, making this estuary an ideal study area for monitoring the water quality in the ACE Basin, as CPA concentrations may have more variability.

The barrier islands that surround St. Helena Sound are composed of beach ridges that formed during the Holocene (Stapor, 1984), and terrestrial and back-barrier sediments including kaolin clays are the primary source of riverine deposits (McIntyre et al., 1991; Soller and Mills, 1991).

An increase in population will inevitably lead to urbanization around the ACE Basin and may result in human-induced stress on the ecosystem. Results from state monitoring programs, specifically the South Carolina Estuarine and Coastal Assessment Program (SCECAP), have already indicated high levels of total nitrogen (34.6-98.5 $\mu \mathrm{M})$, total phosphorous $(2.3-12.49 \mu \mathrm{M})$ and Chl-a (4.1$49.85 \mu \mathrm{g} / \mathrm{L}$ ) when compared to other SC estuaries (Bricker et al., 1999; SCDHEC, 1998). SCECAP randomly samples 30 different sites per year along the SC coast, and resulting water quality data are defined as "good" $\left(<75^{\text {th }} \%\right.$ of historical SC records), "fair" $\left(>=75^{\text {th }}-<90^{\text {th }} \%\right)$, and "poor" $\left(>=90^{\text {th }} \%\right)$. The samples from the ACE Basin revealed that $83 \%$ of open water habitats and $42 \%$ of tidal creek habitats were classified as good, compared to $89 \%$ and $70 \%$ statewide (Van Dolah et al., 2004). Due to the ACE Basin's relatively higher levels of nitrogen, phosphorous, and Chl- $a$, in comparison with levels at another SC NERR in the North Inlet (SC) during 19992000, the estuary was classified as moderately eutrophic (Bricker et al., 1999).

In a recent study in the ACE Basin, measured Chl- $a$ served as a proxy for phytoplankton and indicated the presence of over a hundred phytoplankton species. The majority of these phytoplankton were diatoms, ciliates, and dinoflagellates (including three species associated with harmful algal blooms, Akashiwo sanguinea, Gymnodinium sp., and Heterocapsa rotunda), although no blooms were associated with the samples collected (Keppler et al., 2014).

Harmful algal blooms (HABs) are broadly defined as potentially toxic algal species and high-biomass producers that can cause low oxygen (hypoxia) conditions in the environment and indiscriminant mortalities of aquatic life as they reach dense concentrations, whether or not toxins are present (Heisler et al., 2008). No toxic blooms have been recorded, but low dissolved oxygen (DO; $4.4 \mathrm{mg} / \mathrm{L}$ ) levels in the ACE Basin have been measured, as well as in similarly sized southeastern estuaries (Keppler et al., 2014).

\section{METHODS}

\section{FIELD TECHNIQUES:}

Field campaigns were conducted in summer 2015 and 2016 during the months of June, July, and August, as Chl- $a$ concentrations tend to be higher in summer months. Field days were scheduled to correlate with the day closest to the Landsat 8 TM flyover, and no field day occurred more than 3 days from the time of satellite flyover so that water conditions at time of collection were similar to water conditions at the time of satellite flyover. Field stations were evenly distributed

Table 2. Field station descriptions. Site coordinates, mean depth, distance to nearest land, and land cover type listed by associated water body type.

\begin{tabular}{|c|c|c|c|c|c|c|c|}
\hline Station & Description & $\begin{array}{c}\text { Water } \\
\text { Body } \\
\text { Type }\end{array}$ & $\begin{array}{c}\text { Latitude } \\
\mathbf{( d d})\end{array}$ & $\begin{array}{c}\text { Longitude } \\
(\mathbf{d d})\end{array}$ & $\begin{array}{c}\text { Mean } \\
\text { Depth }(\mathbf{m})\end{array}$ & $\begin{array}{c}\text { Distance to } \\
\text { Nearest Land } \\
(\mathbf{k m})\end{array}$ & $\begin{array}{c}\text { Land Cover } \\
\text { Type }\end{array}$ \\
\hline $\mathbf{2}$ & Atlantic Ocean & $\mathrm{O}$ & 32.45697 & -80.32369 & 5.75 & 2.5 & $\mathrm{D}$ \\
$\mathbf{3}$ & Atlantic Ocean & $\mathrm{O}$ & 32.44956 & -80.35464 & 4.97 & 3.6 & $\mathrm{D}$ \\
$\mathbf{4}$ & St. Helena Sound & $\mathrm{E}$ & 32.44611 & -80.40414 & 9.81 & 3.3 & $\mathrm{H}$ \\
$\mathbf{5}$ & St. Helena Sound & $\mathrm{E}$ & 32.46989 & -80.45122 & 7.77 & 3.4 & $\mathrm{H}$ \\
$\mathbf{6}$ & St. Helena Sound & $\mathrm{E}$ & 32.48672 & -80.48078 & 8.88 & 1.2 & $\mathrm{H}$ \\
$\mathbf{1 1}$ & St. Helena Sound & $\mathrm{E}$ & 32.46289 & -80.42064 & 5.64 & 1.5 & $\mathrm{H}$ \\
$\mathbf{7}$ & Ashepoo/Combahee River & $\mathrm{R}$ & 32.50286 & -80.5125 & 8.84 & 3.6 & $\mathrm{EF}$ \\
$\mathbf{8}$ & Edisto River & $\mathrm{R}$ & 32.53761 & -80.40169 & 6.94 & 0.7 & $\mathrm{EF}$ \\
$\mathbf{1 0}$ & Edisto River & $\mathrm{R}$ & 32.523 & -80.35894 & 1.95 & 1.0 & $\mathrm{EF}$ \\
$\mathbf{1}$ & Big Bay Creek & $\mathrm{R}$ & 32.50339 & -80.32475 & 4.77 & 0.2 & $\mathrm{DF}$ \\
\hline
\end{tabular}


through varying environments in the basin (riverine, estuarine, and offshore) and land classes to capture a range of water quality variability. With a total of 10 stations (Table 2), 4 were riverine (R), 4 were estuarine (E), and 2 were offshore $(\mathrm{O})$; all were near developed (D), herbaceous $(\mathrm{H})$, evergreen forest (EF), and deciduous forest land types (DF) (Table 2). GPS waypoints were also taken at each field station using a Garmin GPSMAP 78c with an accuracy of $3 \mathrm{~m}$ to confirm accurate revisits on each cruise and to further aid in navigating around sandbars, based on previous track lines. Each environment was representative of different interactions between hydrologic, geologic, and biologic cycles.

At each site, subsurface water samples were collected at a depth of $0.5 \mathrm{~m}$ and preserved on ice during transport for laboratory processing. The water samples for CDOM were collected in $50 \mathrm{~mL}$ glass amber bottles to reduce exposure to sunlight and stored on ice. The samples were transported on ice at the completion of the field day and immediately stored in a $4^{\circ} \mathrm{C}$ refrigerator at the aquatic remote sensing laboratory at the College of Charleston until further analysis. Using the following methods outlined in Arar and Collins (1997), water samples for Chl- $a$ analysis were filtered under minimal light exposure using handheld pumps, filtering $500 \mathrm{~mL}$ of water through $0.7 \mu \mathrm{m}$ ashed $\mathrm{GF} / \mathrm{F}^{\mathrm{TM}}$. The filters were then folded inward two times and inserted into a $15 \mathrm{~mL}$ plastic screw cap centrifuge tube, wrapped in aluminum foil to prevent further light penetration, and transferred to a $-20^{\circ} \mathrm{C}$ freezer until further analysis.

The same method of filtering was used for TSM, using preweighed ashed filters for the preparation of gravimetric analysis. Once filtration was complete, the TSM filters were placed in a sealed plastic container wrapped in aluminum foil and stored in a dark environment. The field water quality parameters of $\mathrm{pH}$, salinity, temperature, turbidity, total dissolved solids, and fluorescence were measured in situ using a submersible multiparameter sonde (YSI 6600V2). At each station, the YSI was deployed from the research vessel and lowered to approximately 1 meter below the surface before measurements were recorded.

The spectral radiance of the water was measured from above the water surface, and downwelling irradiance was measured from a ground platform aboard the research vessel at each station using a GER1500 spectroradiometer. This sensor can measure wavelengths in the $350-1050 \mathrm{~nm}$ portion of the spectrum and has a resolution of $1 \mathrm{~nm}$. At each station, four measurements were captured: (1) $45^{\circ}$ down from the horizon of the water (TAR 45), (2) $90^{\circ}$ from the horizon into the water (TAR 90), (3) $45^{\circ}$ from the zenith into the sky (TAR Sky), and (4) zenith into the sky using a cosine diffuser for solar irradiance (Mobley, 1999). The sensor was programmed to take the average of three spectral readings to reduce noise, and multiple spectral readings were taken at each site to account for differences in the target and to decrease potential error in the data. A white reference spectralon was used to calibrate the sensor at each site prior to taking target measurements. This method is described by Duffie and Beckman (2013) and has been successfully applied in similar remote sensing studies (Rodriguez-Guzman and GilbesSantaella, 2009; Ali et al., 2013). Remote sensing reflectance $\left(\mathrm{R}_{\mathrm{RS}}\right)$ was calculated using Eq. 5:

$$
\text { (5) } R_{R S}=\frac{L_{t}-f L_{s}}{E_{d}}
$$

where $L_{t}(\lambda)$ is the radiance measured $45^{\circ}$ from the horizon to the water; $f$ is the Fresnal number, which is the percent of radiation reflected back into the atmosphere; $L_{s}(\lambda)$ is the radiance from the sky; and $E_{d}$ is the solar irradiance measured at the surface $\left(f=0.028\right.$ at a $45^{\circ}$ angle into the water). Remote sensing reflectance, measured in units of steradians $\left(\mathrm{sr}^{-1}\right)$ from radiometric measurements, was used during model development. The $\mathrm{R}_{\mathrm{RS}}$ spectra from each station were averaged to a $10 \mathrm{~nm}$ spectral resolution to enhance the signal-to-noise ratio and trimmed to reflectance data between $400 \mathrm{~nm}$ and $800 \mathrm{~nm}$, as spectral features of observed CPAs are most prominent in this range, and absorption by water is observed in lower wavelengths.

\section{LABORATORY ANALYSIS}

The Chl- $a$ concentrations were measured following the US EPA 445 acetone extraction protocol outlined in Arar and Collins (1997). Once ready to process, the samples were removed from the freezer and thawed until they reached room temperature, and $10 \mathrm{~mL}$ of $90 \%$ buffered acetone solution was added to the centrifuge tube to degrade the filter. The filter in each sample was macerated to disintegrate the Chl- $a$ samples from the GFF. Samples were then placed in a $4 \mathrm{C}$ refrigerator for 24 hours to complete the extraction process. Subsequently, the samples were removed from the refrigerator and spun in a centrifuge at 4,000 RPM for 10 minutes at $10 \mathrm{C}$. This controlled temperature during centrifugation allows the samples to undergo a slower warming process while the filters are separated from the supernatant. The Chl- $a$ concentration was measured by the fluorescence value of each sample, using the Turner Designs Trilogy Fluorometer fitted with a chlorophyll optical module (485 nm excitation and emission filter $665 \mathrm{~nm}$ ).

Gravimetric analysis was used to measure the concentrations of inorganic and organic material in the water at each sampling location. Following the EPA protocol outline in Arar and Collins (1997), ashed filters were weighed before the samples underwent gravimetric analysis. After 500 $\mathrm{mL}$ of water from each site was filtered, the filters were dried at $60 \mathrm{C}$ for 12 hours in an Isotemp oven. The dried filters were then removed from the oven and weighed once they reached room temperature to determine the mass of TSM 
(TSM $=$ dry filter weight - pre-filter weight). After the TSM concentrations were determined, the relative reflectance of the remaining particles on the filter samples was measured at $1 \mathrm{~nm}$ resolution using a portable ASD spectroradiometer and $\mathrm{R}$-software. Once relative reflectance was measured, the filters were combusted in an Isotemp Muffle Furnace at $550^{\circ} \mathrm{C}$ for 4 hours to remove organics and weighed again to measure the organic carbon content lost on ignition (LOI). The relative reflectance of the combusted filters was measured a second time to characterize the inorganic particles. These signatures were then utilized during data processing, analyzing, and developing models.

Organic materials that have dissolved into the water system strongly contribute to the water's ability to absorb or reflect and are therefore a main focus in many ocean color optics studies (Babin et al., 2003; Miller et al., 2002). The water samples stored in the $50 \mathrm{~mL}$ amber bottles were prepared using the methods proposed by Mitchell et al. (1998). Each sample was filtered through a nylon filter with a $0.2 \mu \mathrm{m}$ pore size to remove any suspended particles. The absorption spectra of the CDOM samples were then measured using an Evolution 220 spectrophotometer fitted with a $100 \mathrm{~mm}$ long quartz cell to provide an appropriate path length for light absorption. The concentration of CDOM is a function of the slope of absorption. Higher slopes in the UV-blue portion of the spectrum indicate higher concentrations and vice versa. The spectral slope was calculated from 400-450 $\mathrm{nm}$ and graphed by station to identify stations with greater concentrations of CDOM.

\section{PARTIAL LEAST SQUARES REGRESSION MODEL DEVELOPMENT:}

Multivariate data analysis and feature extraction methods were applied to in situ hyperspectral data as a means to identify the CPAs in the water. Statistical analyses of the hyperspectral data included partial least square regression (PLSR), multivariable regressions, and principal component analysis (PCA) using Minitab and ExcelStat. These methods have numerous advantages over traditional band ratios, as they can be calibrated using the full available spectrum, rather than specific spectral ranges.

Hyperspectral datasets can identify important absorption features that may be characteristic of various CPAs, including Chl- $a$, which can be undetectable by sensors with moderate resolution (Cole et al., 2014). Due to the amplified spectral resolution, these datasets contain a vast quantity of repetitive information that increase the multidimensionality of the data, which consequently needs a method of its own to decrease the dimensionality between variables in the data (Gomez-Chova et al., 2003). Prior to statistical analysis, in situ GER data was standardized to relative reflectance values and normalized to establish proper modeling across varying spectral characteristics, and the radiometric resolution was decreased from $1 \mathrm{~nm}$ to $10 \mathrm{~nm}$ to reduce noise.

Recall that VPCA is a statistical method that forms new variables that are linear transformations of the original variables (Nwaodua et al., 2014). The new variables produced after reducing the dimensionality of the initial dataset are uncorrelated and exemplify a large percentage of the information from the original variables. VPCA was applied to first-derivative in situ GER data using XLSTAT Statistical Software to decrease the dimensionality of the data and to identify the relevant band characteristic of each component. The relative reflectance values between 400 and $800 \mathrm{~nm}$ were evaluated at a $10 \mathrm{~nm}$ resolution to produce principal component scores in each band. These scores were compared with spectrums of known constituents in southeastern and ACE Basin waters.

PLSR is comparable to PCA in that reflectance spectra are influenced by components of linear combinations for observed explanatory variables (spectral bands), but PLSR surpasses PCA as it can correlate components to response variables (CPAs). PLSR was applied to relative reflectance of in situ GER data and in situ Chl- $a$, TSM, TSS, and CDOM concentrations to develop a regression model with an optimal number of factors to be useful for predicting CPAs. The "leave one out" cross-validation method described in Haaland and Thomas (1988) was used to select the optimal number of factors without over-fitting the concentration data using XLSTAT Statistical Software and Minitab 17. This method was chosen for this study as it considers the complexity of the datasets and contributes a more robust predictive model calibrated to the estuarine waters of the ACE Basin.

\section{RESULTS AND DISCUSSION}

\section{COLOR-PRODUCING AGENTS}

ACE Basin waters are characterized by multiple nonlinearly related optically active constituents (Figure 2). Minor to no correlations between Chl- $a$ and TSM $\left(\mathrm{R}^{2}=0.19\right)$ in Figure $2 \mathrm{a}$ and Chl- $a$ and CDOM $\left(\mathrm{R}^{2}=0.06\right)$ in Figure $2 \mathrm{~b}$ indicate that the CPAs are independent of one another. The measurements of CPAs were relatively high when compared to turbid waters in similar coastal watersheds (Schalles, 2006; Keppler et al., 2015). The TSM values ranged between 60.4 and $155.2 \mathrm{mg} / \mathrm{L}$, with an average concentration of 87.7 $\mathrm{mg} / \mathrm{L}$ and a SD of $15.6 \mathrm{mg} / \mathrm{L}$. The greatest average TSM concentrations were measured at stations 1 and 8, which had the highest TSS concentrations and were closest to land. The lowest concentrations were measured at stations $5(60.8 \mathrm{mg} / \mathrm{L})$ and $7(60.4 \mathrm{mg} / \mathrm{L})$ (Figure 3). However, these stations were near major sandbars within the Sound, so the rates of flow may have been constrained, causing lower concentrations of suspended matter (Milligan et al., 2001). In 


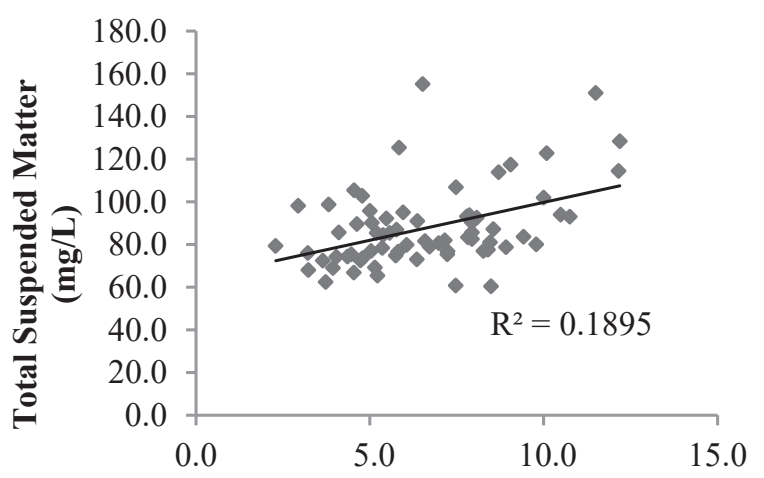

(a)

Chlorophyll- $a(\mu \mathrm{g} / \mathrm{L})$

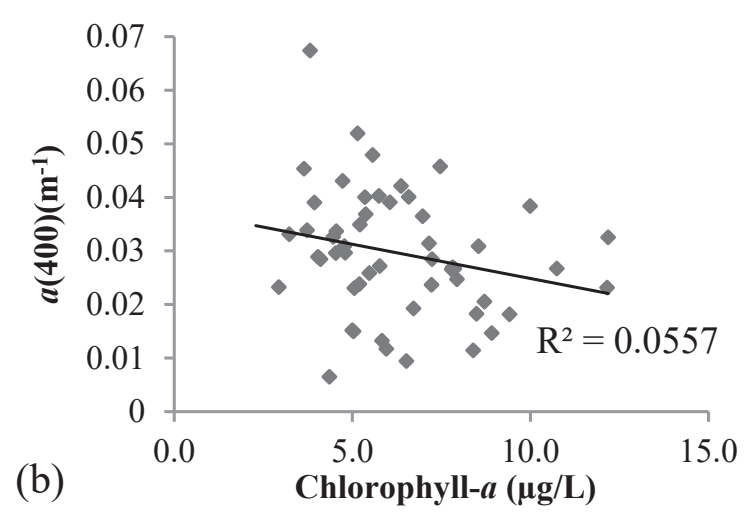

Figure 2. Regression plots of (a) Chl-a vs. TSM and (b) Chl-a vs. CDOM absorption (aCDOM) at $400 \mathrm{~m}^{-1}$.
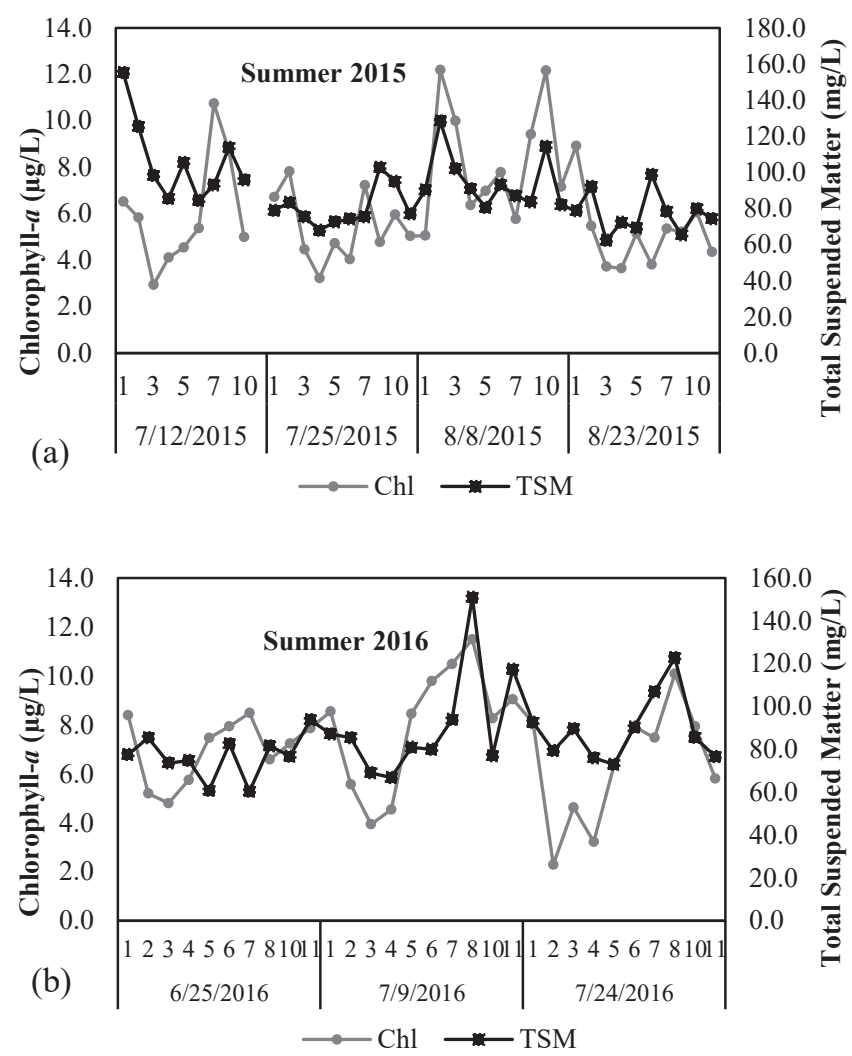

Figure 3. Chl-a and TSM concentrations by site and by field sampling day for (a) summer 2015 and (b) summer 2016. general, the most variations in TSM were observed at stations with the highest average TSM and Chl- $a$ concentrations, which were in smaller water bodies with shallower depths. This suggests that the constituents vary independently from each other; however, similar biogeochemical conditions may influence the variations between them. The spatial patterns of these components are essential to understanding the processes influencing their distribution and accumulation throughout the ACE Basin. Only twice were TSM and Chl- $a$ concentrations equally high, both times at station 8 , which is in Fenwick Cut, where the Edisto River mixes with the Intracoastal Waterway (ICW). This is a highly traversed area known to have high flocculating, low-settling sediments after periods of increased discharge. Bottom stress from current mixing and increased discharge resuspends the flocs (Milligan et al., 2001), causing elevated concentrations of TSM and Chl- $a$ in this location.

The results indicate that average CPA concentrations follow a nearshore-offshore gradient, with the stations nearest land having the highest concentrations of Chl- $a$ and TSM, and the sites furthest from land having the lowest (Figure 3). These trends are comparable to other nearshoreoffshore gradient studies in coastal watersheds (Smith, 2002; Schalles, 2006; Keppler et al., 2015) and support the concept that terrigenous runoff gradually attenuates as it travels farther from land.

In this study, absorption by CDOM decreased exponentially with increasing wavelength. Absorption coefficients at $400 \mathrm{~nm}$ (a400) from both field seasons ranged from -0.38 to $10.2 \mathrm{~m}^{-1}$, with an average of $3.16 \mathrm{~m}^{-1}$ and a standard deviation (SD) of $1.99 \mathrm{~m}^{-1}$ (Figure 4). This wide range and high SD can be attributed to high variability among field stations and possibly temporal variations. To investigate the role of temporal variations, the $\mathrm{CDOM}$ values were analyzed by field season. Absorption coefficients at 400 $\mathrm{nm}$ for summer 2015 ranged from -0.38 to $5.86 \mathrm{~m}^{-1}$, with an average of $2.32 \mathrm{~m}^{-1}$ and an SD of $1.16 \mathrm{~m}^{-1}$ (Figure 5a). During the summer of 2016, an increase in values were observed, as the range of absorption coefficients at $400 \mathrm{~nm}$ was 0.62 to $9.62 \mathrm{~m}^{-1}$, with an average of $4.17 \mathrm{~m}^{-1}$ and an SD of $2.33 \mathrm{~m}^{-1}$

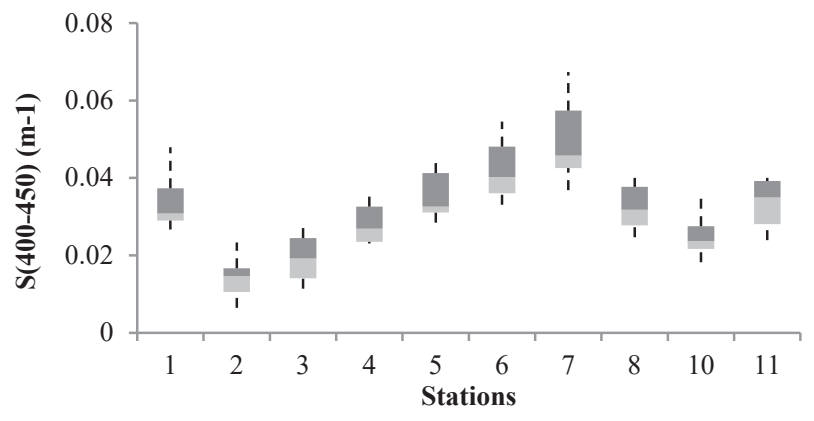

Figure 4. Box plots of spectral slope of CDOM from 400nm to 450 $\mathrm{nm}$. Box plots include minimum, Q1, median, Q3, and maximum. 

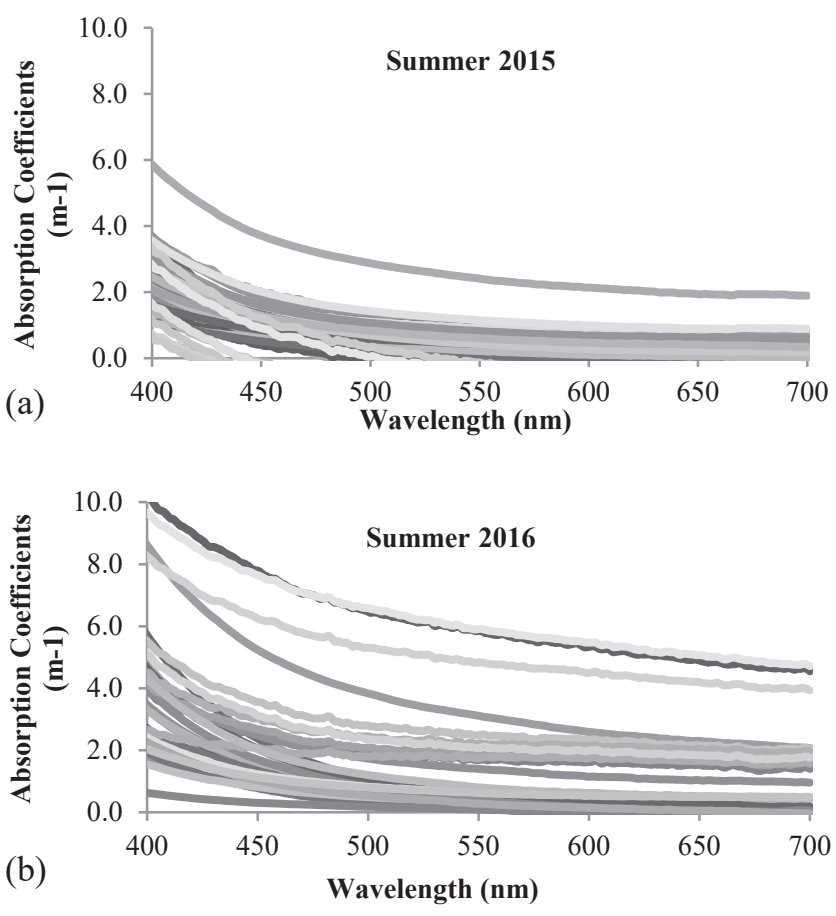

Figure 5. CDOM absorption spectra from 400 to $700 \mathrm{~nm}$ using laboratory spectrophotometer: (a) summer 2015 spectra and (b) summer 2016 spectra.

(Figure 5b). The stations that had the highest absorption coefficients for both field seasons were $1,7,8$, and 11 , while the lowest values were observed at stations 2,3 , and 10 . The CDOM absorption coefficients were highest at station 1 and 7, which were upstream from the Sound. Station 1 is in Big Bay Creek, adjacent to Live Oak Boat Landing, which is part of Edisto Beach State Park and is influenced by runoff from the boat landing and surrounding areas of anthropogenic activity. Sources of CDOM at this location may include marsh grass and decaying leaves from deciduous trees within the State Park. Station 7 is in the Ashepoo river surrounded by Spartina alternaflora (marsh grass), which is an important source of CDOM in estuaries, as it is salt tolerant, making it the dominate plant life. CDOM decreases at mixing gradients (stations 8 and 10) and is lowest in the Sound and offshore due to high loads of seston dominating the water (Schalles, 2006).

\section{REMOTE SENSING}

Laboratory-analyzed Chl- $a$ and TSM concentrations were correlated with variations in radiometric measurements of TSM filters. Stronger absorption troughs and reflectance peaks coincided with stations with high observed TSM and Chl- $a$ concentrations. The troughs (see Figures 2 and 3) indicate spectral absorption features of TSM, while the peaks indicate spectral reflectance features of TSM. The point of inflection at $660 \mathrm{~nm}$ is representative of high TSM absorption along with the interplay of seston scattering and higher water absorption in this spectral region (Schalles, 2006) (Figure 6).

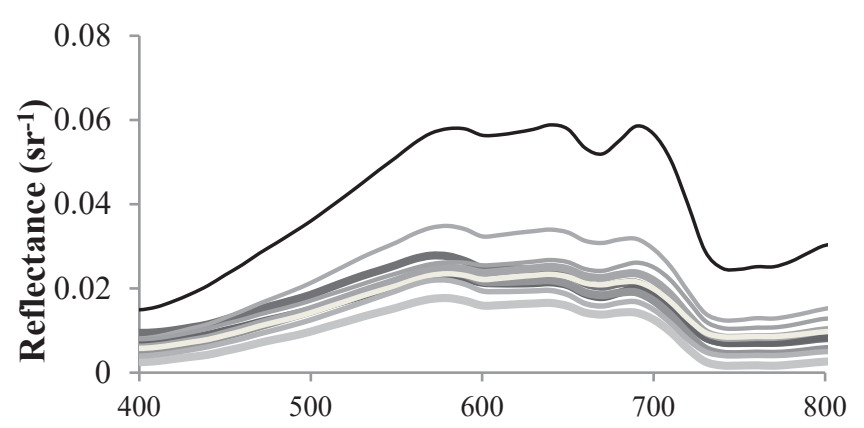

Figure 6. Remote sensing of reflectance spectra from summer 2015 field campaign.

The characteristic troughs and peaks observed throughout each spectra indicate the existence of organic matter (D'Sa and Miller, 2005) along with the low reflectance in the blue portion of the spectrum. Low reflectance in the red portion of the spectrum can be attributed to absorption by Chl- $a$, specifically near 650-690 $\mathrm{nm}$. Absorption troughs from algal particles were no longer present as organics were removed, and the magnitude of the reflectance peaks shifted toward longer wavelengths with an observed peak around $580 \mathrm{~nm}$, consistent with reflectance patterns from high concentrations of kaolin clays (Beck et al., 1976).

\section{APPLICATION OF BAND RATIO ALGORITHMS}

Six published algorithms were assessed to model Chl- $a$ variability in the study areas, and no correlations were observed between the in situ Chl- $a$ data and the modeled data (Table 1). However, the models that preformed relatively better were adapted using estimated correlation coefficients determined from the in situ data. The correlations ranged between 0.0026 and 0.15 for the blue-green band ratios regressed with laboratory-analyzed Chl- $a$ concentrations, with the strongest correlation resulting from tuning the OC4v4 algorithm, which was a red-NIR/blue-green model developed for global ocean systems, with a strong reflectance peak at $580 \mathrm{~nm}$. In general, all the band ratio models were equally weak in terms of performance in predicting Chl- $a$ concentration. With all the $\mathrm{R}^{2}$ values consistently $<0.2$, no correlations or assumptions could be made using the band ratio models, as they were not statistically significant (Table 1). Even though the waters within the ACE Basin contained moderate amounts of Chl-a, the high concentration of suspended sediment and CDOM most likely caused spectral mixing within the blue-green, and red-NIR spectral range, which impeded the reflectance and absorbance by the Chl- $a$ to the sensor. The Morel models applied to the hyperspectral GER dataset significantly overestimated Chl- $a$, specifically when the measured concentrations were low at stations 4 and 5 throughout each season. In these cases, strong absorption occurred in the blue and green wavelengths, most likely due to a greater presence of seston (Schalles, 2006), which caused 
the logarithm of the blue-green ratio to be negative (D'Sa and Miller, 2005).

For the OC4v4 and Hladik models, predicted Chl-a concentrations were lower than the measured concentrations; however, they were closer to actual values, suggesting that models accounting for more spectral features are more successful. Spectral similarities, low-to-moderate spatial variability, and low-to-moderate Chl- $a$ concentrations made it difficult for the models to accurately predict Chl- $a$. Additionally, these blue-green models were developed from a global dataset of Case I waters where Chl- $a$ is the dominant constituent and with a much broader range in concentrations. Therefore, when applied to the complex waters of the ACE Basin, the models performed poorly.

Tuning and calibration of the OC4v 4 model resulted in slightly higher predictive accuracy $(0.8 \%)$ when applied to the ACE Basin than current global ocean color models. This model used spectral features from both blue-green and red-NIR wavelengths to account for the optical complexity in southeastern estuarine waters (Schalles, 2006). Distinguishing spectral signatures of the water column is vital when choosing bands that exemplify CPAs. However, this model did not result in any accurate predictions of Chl- $a$, as the correlations remained extremely weak $\left(\mathrm{R}^{2}=\right.$ 0.15 , RMSE $=2.22$ ). The low-to-moderate concentrations of measured Chl- $a$ combined with spectral mixing throughout the measured bands contributed to a low signal-to-noise ratio, which likely caused all models to underperform.

\section{APPLICATION OF PRINCIPAL COMPONENT ANALYSIS}

The ACE basin has an optically complex environment resulting from the varying biological and sedimentological particles in the water. An awareness of the water constituents that represent this aquatic system is critical for ocean color modeling. The VPCA model, based on the entire dataset, indicated the presence of three significant varimax-rotated factors, which account for $54.9 \%, 27.7 \%$, and $8.8 \%$ of the variance, for a combined total variance explained of $91.3 \%$ (Figure 7). A comparison of the factor loadings as a function of wavelength indicated that the components consisted of organic and inorganic materials. PC1 and PC3 did not display any identifiable spectral features indicative of water constituents and were most likely backscatter from high sediment loading and re-suspension within the water column from boats, waves, or high-discharge events. The spectral peaks from PC2 were comparable to the patterns observed in the GER data and were characterized by reflectance trends indicative of Chl-a (Figure 8). In situ GER reflectance of surface water indicated moderate concentrations of Chl- $a$, with spectral features at $550 \mathrm{~nm}$ comparable to those of the cyanobacteria Anabaena, which is known to travel among areas of moist sediment (Romero-Vivas, 2015). This may explain why some stations exhibited high TSM and
Chl- $a$, as the sediments may have served as vehicles for the organic particles (Stumpf et al., 1988). The effectiveness of the PCA modeling technique emanates from its capacity to distinguish linear combinations of the original variables that are independent and to acknowledge the issue of correlated variance. The organic and inorganic CPAs present in the ACE Basin characterize these waters as optically complex, particularly after meteorological disturbance events from high wind or precipitation.

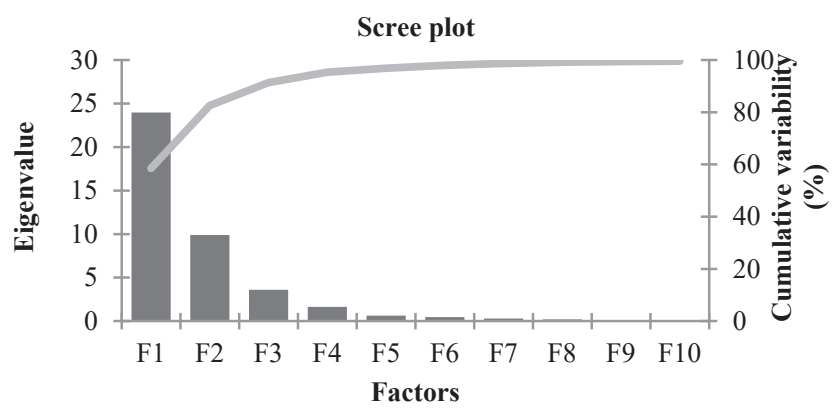

Figure 7. Scree plot of variability (\%) and cumulative variability (\%) of each component.
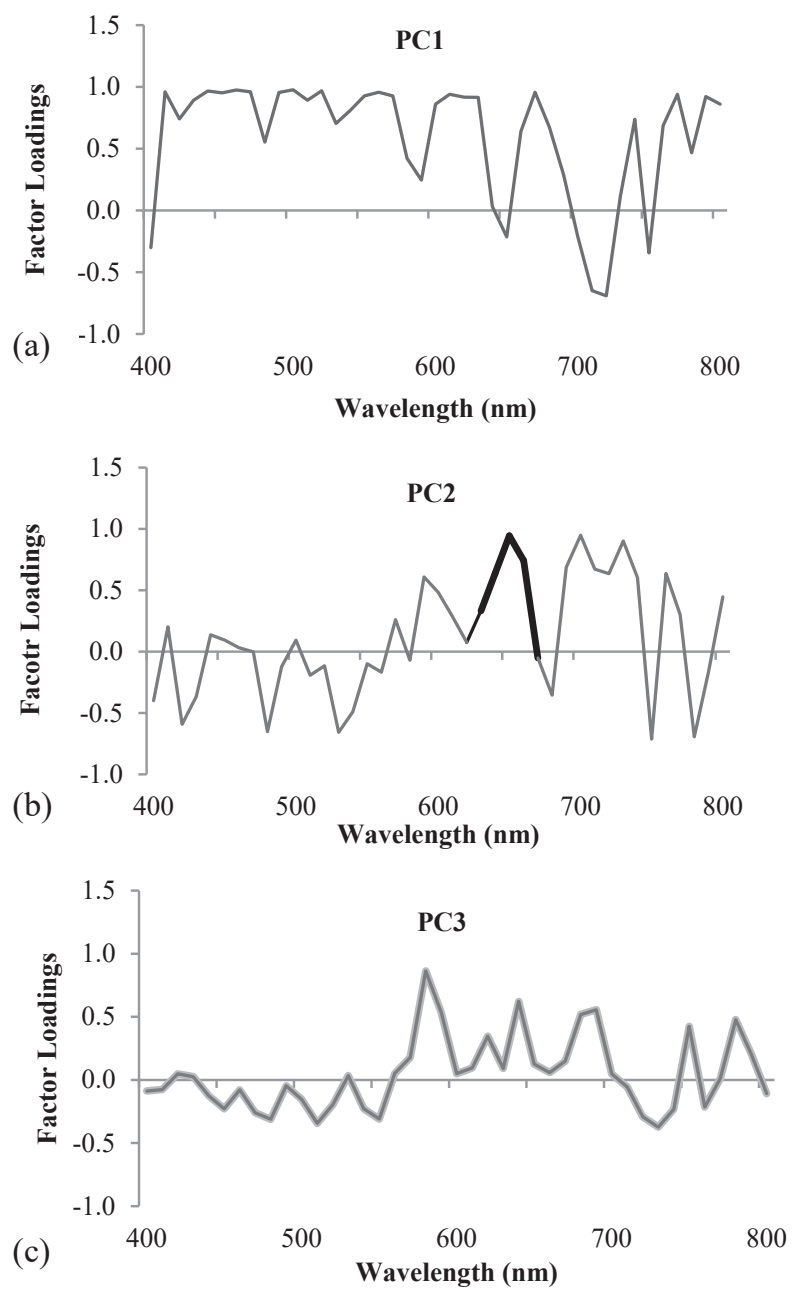

Figure 8. Weighted scores of the first three PCs. Highlighted reflectance peak (black) in PC2 (b) is characteristic of a spectral feature of $\mathrm{Chl}-\mathrm{a}$. 


\section{APPLICATION OF PARTIAL LEAST SQUARES REGRESSION}

The PLSR model for the estimation of Chl- $a$ using the full spectrum of hyperspectral GER data was stronger with a lower error rate $\left(\mathrm{R}^{2}=0.49\right.$ and $\left.\mathrm{RMSE}=1.77 \mu \mathrm{g} / \mathrm{L}\right)$ can be observed in Figure 9. Chl- $a$ values from station 1 were removed in this model to decrease outliers. A nearlinear correlation with few outliers between the predicted and observed Chl- $a$ values demonstrates the potential for predictive ocean color monitoring in the ACE Basin (Figure $8 \mathrm{a}$ ). Standardized coefficients of bands 420, 550, and $680 \mathrm{~nm}$ showed the greatest sensitivity for predicting Chl- $a$ (Figure 9b). These bands are characteristic of the absorption and reflection features of the planktonic cyanobacteria that are typically found in temperate waters in the southeast.

A PLSR model for the estimation of TSM was not as accurate, with an $\mathrm{R}^{2}=0.40$, and the error rate was much higher in this model (RMSE $=12.9 \mathrm{mg} / \mathrm{L})$, especially at stations 1 and 8 , which caused deviation from the model (Figure 9a). This was likely due to the lower spectral variability observed at these stations from high loads of inorganic material that were characterized by absorption features. More absorption was apparent with TSM than with Chl- $a$, with dominating troughs at 460, 490, 660 (Figure 10b), and the NIR portion of the spectrum. TSS preformed less moderately than Chl- $a$ and TSM, with an $\mathrm{R}^{2}$ value of 0.26 (Figure $11 \mathrm{a}$ ), a strong reflectance peak at 580 and $590 \mathrm{~nm}$, and strong absorption along NIR wavelengths (Figure 11b). Although satellite estimation proved to be difficult in such shallow, spatially confined waters, Stations 1 and 8 provided an understanding of the spectral characteristics of ACE Basin waters with high CPA concentrations. These stations, along with offshore stations, also contributed to the variability in concentrations, which is important when developing a regional model for remote estimation. Using more of these types of signatures to train the model would likely improve the model strength and estimation.

Overall, two primary factors can contribute to the low correlations from PLSR: (1) The optically complex nature of these waters prevented electromagnetic radiation from penetrating the sub-bottom, particularly at shallow sites with high suspended sediments and varying angles of incoming radiation. Significant backscatter from the bottom decreased

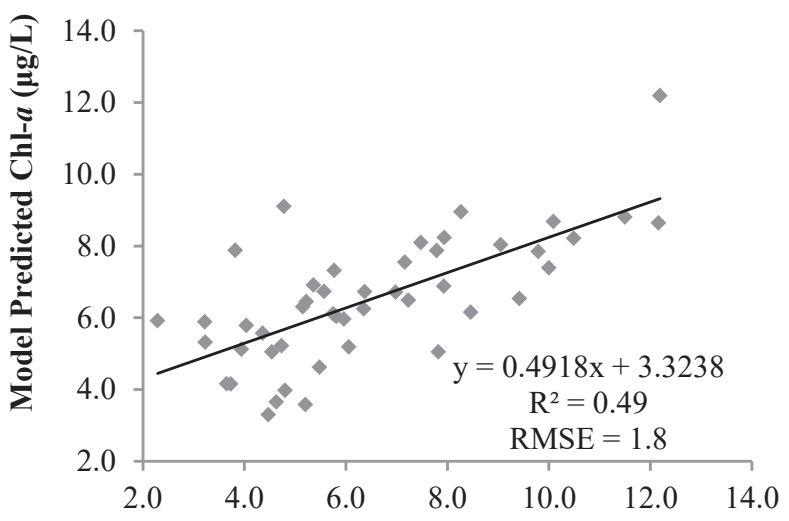

(a)

Observed Chl- $a(\mu \mathrm{g} / \mathrm{L})$

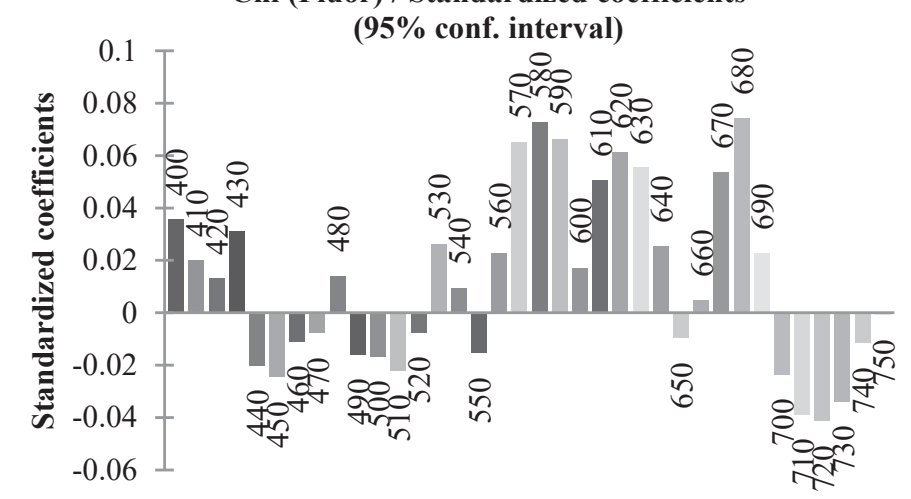

(b)

Wavelength (nm)

Figure 9. (a) PLSR model accuracies for Chl-a prediction and (b) PLSR standardized coefficient plot for Chl-a prediction.

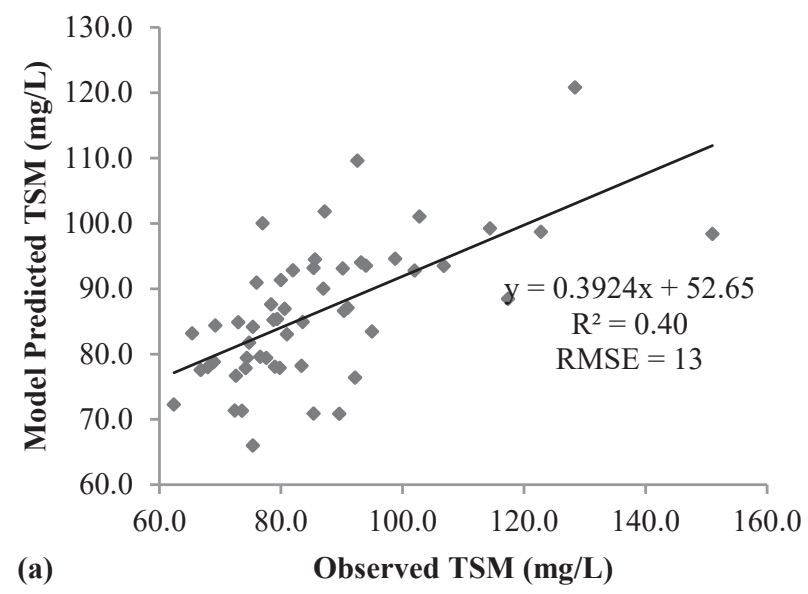

TSM / Standardized coefficients (95\% conf. interval)

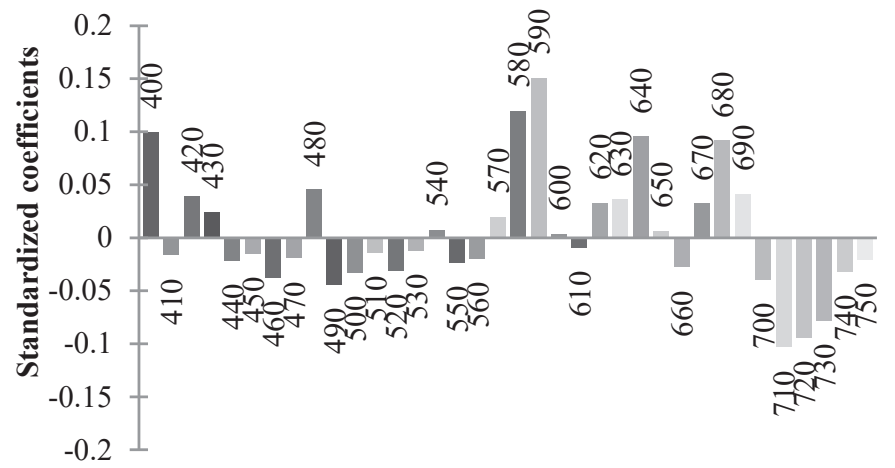

(b)

Wavelength (nm)

Figure 10. (a) PLSR model accuracies for TSM and (b) PLSR standardized coefficient plot for TSM. 


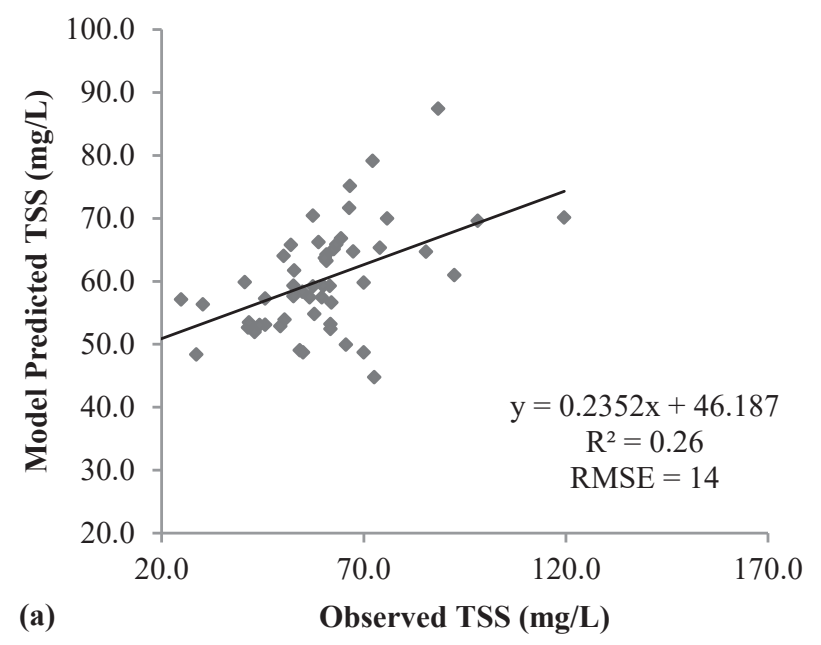

TSS / Standardized coefficients (95\% conf. interval)

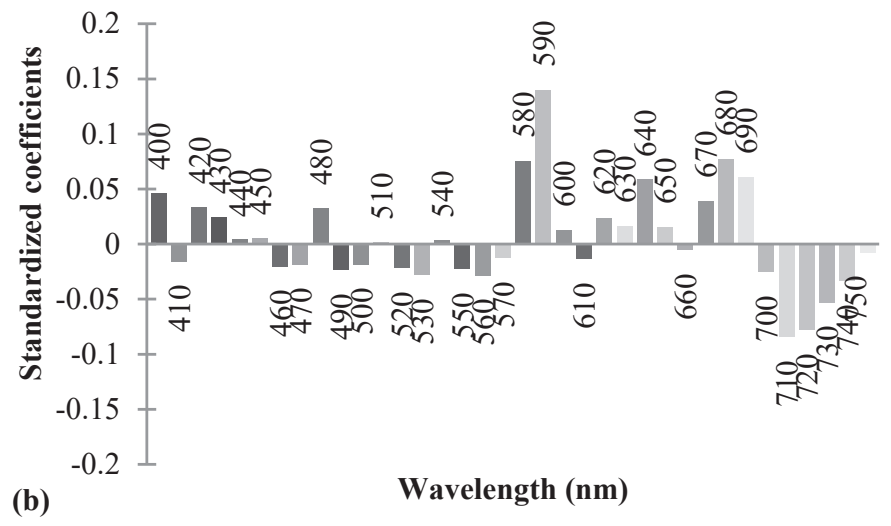

Figure 11. (a) PLSR model accuracies for TSS and (b) PLSR standardized coefficient plot for TSS.

the signal-to-noise ratio from the water surface to the sensor. (2) Significantly high inorganic concentrations observed in all the data, along with high CDOM absorption coefficients, reduced the signal strength and signal variability. The primary factors made it challenging for the model to distinguish background noise (e.g., backscattering from the bottom and other in-water optical constituents) from the spectral features of Chl- $a$. To enhance the signal-to-noise ratio, more refined models or methods are necessary to appropriately distinguish the individual signals. These models should take into consideration the diffuse attenuation coefficients of the water column, bottom reflectance, interference from the seaair interface, and depth (Lee et al., 2005).

\section{CONCLUSION}

In this study, in situ sampling of water quality parameters was used to characterize the temporal and spatial variability in the ACE Basin waters. The results indicate optically complex, moderately eutrophic waters with low-to-moderate concentrations of Chl- $a$ and high TSM and CDOM. Distance from land and the degree of watershed development were also parameters that influenced the presence of Chl- $a$ and suspended sediments. The results of this study indicate close linkages between physical and bio-optical properties of the water column, which makes satellite remote sensing a useful tool for monitoring changes.

The traditional band ratio models for ocean color or estuarine modeling that have been proposed in previous studies were not found to be a beneficial or an accurate method for estimating Chl- $a$ from the in situ radiometric data $\left(\mathrm{R}^{2}<0.099\right)$ due to significant overestimation and underestimation. Tuning the OC4v4 model using model coefficients derived from the in situ data slightly improved the overall accuracy $\left(\mathrm{R}^{2}=0.15\right)$ and lowered the error rate $($ RMSE $=2.2)$; however, numerous factors contributed to a low signal-to-noise ratio, which limited its success. More spatially distributed stations with higher spectral variability and more representative data, combined with enhancements in atmospheric correction methods and the availability of higher-resolution sensors, will lead to more conclusive predictions of CPA variability.

The multivariate PLSR approach provided a more accurate model for predicting Chl- $a\left(\mathrm{R}^{2}=0.49\right)$ and TSM $\left(\mathrm{R}^{2}=0.40\right)$ than the traditional band ratio approach. Employing the full visible-near infrared spectrum improved the modeling capability, even with a low signal-to-noise ratio. PLSR was useful for reducing the dimensionality and multicollinearity of the extensive hyperspectral dataset while maintaining maximum variability among observations. This approach demonstrated the favorable potential for modeling CPA variability in the ACE Basin despite the dominating properties of inorganic materials in the water.

As operational ocean color satellites become more abundant and higher-resolution technologies are employed, multivariate methods, including PLSR, display considerable potential for estimating CPAs in the ACE Basin. These methods can also be applied to predict CPAs in other coastal systems, but sample collection and field calibration would be required, as the ACE Basin models lack correlations strong enough to predict CPA variability elsewhere. These technologies would also allow for more modeling and prediction of water quality that could be utilized by resource managers to accurately monitor and protect aquatic ecosystems. The absorption and reflectance features characterizing sediments and algal species make it difficult for moderate resolution sensors to distinguish in situ concentrations. The results from this study provide a strong foundation for the future of water quality monitoring and the protection of biodiversity in the ACE basin, and successful application of the PLSR approach demonstrates substantial potential for future remote sensing research. This is a considerable benefit for coastal resource 
managers because the technique applies a versatile approach that can be used in an array of waters. The results provide a synoptic view of the water quality variations in a significantly short amount of time, which could facilitate coastal managers in making informed decisions about potential sources of pollution, land development, and health for humans and the surrounding environment.

Finally, communication with coastal managers and local community members would strongly contribute to this research. Interaction with coastal managers would provide localized knowledge regarding primary concerns with water quality, as well as give insight to the different complicated parameters that may affect specific coastal areas. Additionally, correspondence with local community members would aid in determining the level of awareness, understanding, and concern about anthropogenic factors that may be influencing water quality in these coastal systems.

\section{ACKNOWLEDGEMENTS}

This research was supported by the Kathryn D. Sullivan Earth and Marine Science Fellowship and the Graduate Research Assistantship through the NASA South Carolina (SC) Space Grant Consortium and NOAA SC Sea Grant Consortium. The authors thank Peter Bierce, captain of the research vessel, and the department of Geology and Environmental Sciences at the College of Charleston, South Carolina, for loaning the research vessel and providing equipment, technology, and laboratory space that were paramount to the completion and success of this project.

\section{LITERATURE CITED}

Ali, K. A., Witter, D. L, and Ortiz, J. D., 2013. Multivariate approach to estimate colour producing agents in Case 2 waters using first-derivative spectrophotometer data. Geocarto International 29(2): 102-127.

Allen, J. and Lu, K., 2003. Modeling and prediction of future urban growth in the Charleston region of South Carolina: a GIS-based integrated approach. Conservation Ecology 8(2): 2.

Anderson, D., Glibert, M., Burkholder, P. M., and Joann, M., 2002. Harmful algal blooms and eutrophication: Nutrient sources, composition, and consequences. Estuaries 25(4).

Arar, E.J and Collins, G.B., 1997. Method 445.0: In Vitro determination of chlorophyll a and pheophytin a in marine and freshwater algae by fluorescence. National Exposure Research Laboratory. Office of Research Development, U.S. Environmental Protection Agency: Cincinnati, $\mathrm{OH}$.

Babin, M., Stramski, D., Ferrari, G.M., Claustre, H., Bricaud, A., Obolensky, G., and Heopffner, N., 2003. Variations in the light absorption coefficients of phytoplankton, nonalgal particles, and dissolved organic matter in coastal water around Europe. Journal of Geophysical Research 108(7):3211.

Bannerman, R.T., Owens, D. W., Dobbs, R. B., and Hornewer, N. J., 1993. Sources of pollutants in Wisconsin stormwater. Water Science and Technology 28:241-259.

Bhatti, A. M., Rundquist, D., Schalles, J., Steele, M., and Takagi, M., 2010. Qualitative assessment of inland and coastal waters by using remotely sensed data. International Archives of the Photogrammetry, Remote Sensing and Spatial Information Science 38(8).

Bearden, C., Low, R., Rhodes, R., Van Dolah, R., Wenner, C, Wenner E, and Whitaker, D., 1985. A review and analysis of commercial shrimp trawling in the sounds and bays of South Carolina. South Carolina Marine Resources Center. Technical Report 62.

Beck, R. H., B. F. Robinson, W. W. McFee, and J. B. Peterson, 1976. Spectral characteristics of soils related to the interaction of soil moisture, organic carbon and clay content. LARS Information Note 081176. Laboratory for Applications of Remote Sensing, Purdue University, West Lafayette, IN.

Bricker, S. B., Clement, C. G., Pirhalla, D. E., Orlando, S. P., and Farrow, D. R. G., 1999. National estuarine eutrophication assessment: effects of nutrient enrichment in the Nation's estuaries. NOAA. National Ocean Service, Special Projects Office and the National Centers for Coastal Ocean Science, Silver Springs, MD: 71.

Cole, B., McMorrow, J., and Evans, M., 2014. Empirical modeling of vegetation abundance from airborne hyperspectral data for upland peatland restoration monitoring. Remote Sensing 6: 716-739.

Cooke, C. W., 1936. Geology of the Coastal Plain of South Carolina. United States Department of the Interior. Bulletin 867.

Corbert, C. A., 2007. Color dissolved organic matter (CDOM) workshop summary. Reports. Paper 2.

D'sa, E. J. and Miller, R. L., 2005. Bio-optical properties of coastal waters. Ch. 6 in, Remote Sensing of Coastal Aquatic Environments: 129-155.

Doxaran, D., Froidefond, J. M., and Castaing, P., 2002. A reflectance band ratio used to estimate suspended matter concentrations in sediment-dominant coastal waters. International Journal of Remote Sensing 23: 5079-5085.

Duffie, J. A., and Beckman, W. A., 2013. Solar Engineering of Thermal Processes (4 ed.). Hoboken, NJ: John Wiley \& Sons.

Etheridge, J. R., Brigand, F., and Burchell II, M. R., 2015. Quantifying nutrient and suspended solids fluxes in a constructed tidal marsh following rainfall: The value of capturing rapid changes in flow and concentrations. Ecological Engineering 78: 41-52.

Fu, Y., Yang, G., Feng, H., Song, X., Xu, X., and Wang, J., 2013. Comparative analysis of three regression methods for the winter wheat biomass estimation using hyperspectral measurements. Proceedings of the 2nd International Conference on Computer Science and Electronics Engineering: 1733-1736. Hangzhou, China. 
Gao, B. C., Montes, M. J., Ahmad, Z., and Davis, C. O., 2000. Atmospheric correction algorithm for hyperspectral remote sensing of ocean color from space. Applied Optics 39(6): 887-896.

Gilbert, P. M., Anderson, D. A., Gentien, P., Graneli, E., and Sellner, K. G., 2005a. The global, complex phenomena of harmful algal blooms. Oceanography 18(2): 136-147.

Gitelson, A. 1992. The peak near $700 \mathrm{~nm}$ in the reflectance spectra of algae and water: relationships of its magnitude and position with chlorophyll concentration. International Journal of Remote Sensing 13(17):1367-1373.

Gomez-Chova, J. C., Camps-Valls, G., Martín, J. D., Soria, E., Vila, J., Alonso-Chorda, L., and Moreno, J., 2003. Feature selection of hyperspectral data through local correlation and SFFS for crop classification. IEEE International Geoscience and Remote Sensing Symposium: 555-557.

Gross-Colzy, L., S. C., Frouin, R., and Henry, P., 2007. A general ocean colour atmospheric correction scheme based on principal component analysis-Part I: Performance on case I and case 2 waters. Proc. SPIE, 6680, Coastal Ocean Remote Sensing, 668002.

Gurlin, D., A. A. Gitelson, and Moses, W. J. 2011. Remote estimation of Chl- $a$ concentration in turbid productive waters-Return to a simple two-band NIR-red model? Remote Sensing of Environment 115: 3479-3490.

Haaland, D. M. and Thomas, E.V., 1988. Partial leastsquares methods for spectral analyses. 1. Relation to other quantitative calibration methods and the extraction of qualitative information. Analytical Chemistry 60(11): 1193-1202.

Han, L., 1997. Spectral reflectance with varying suspended sediment concentrations in clear and algae-laden waters. Photogrammetric Engineering and Remote Sensing 63: 701-705.

Heisler, J., Glibert, P. M., Burkholder, J. M., Anderson, D. M., Cochlan, W., Dennison. W. C,. Dortch, Q., Gobler, C. J., Heil, C. A., Humphries, E,. Lewitus, A., Magnien, R., Marshall, H. G., Sellner, K., Stockwell, D. A., Stoecker, D. K., and Suddleson, M., 2008. Eutrophication and harmful algal blooms: A scientific consensus. Harmful Algae 8: 3-13.

IOCCG, 2000. Remote sensing of ocean color in coastal, and other optically complex waters. Dartmouth, Canada: Sathyendranath, S. (ed), Reports of the International Ocean-Colour Coordinating Group, No. 3, IOCCG.(India) Private, Ltd.

Keppler, C. J., Bergquist, D. C., Brock, L. M., Felber, J., and Greenfield, D. I., 2014. A spatial assessment of baseline nutrient and water quality values in the AshepooCombahee-Edisto (ACE) Basin, South Carolina, USA. Marine Pollution Bulletin 99:332-337.

Klemas, V., 2011. Remote sensing techniques for studying coastal ecosystems: an overview. Journal of Coastal Research 27(1).

Lee, Z., Carder, K. L., Hawes, S. K., Steward, R. G., Peacock, T. G., and Davis, C. O. 1994. Model for the interpretation of hyperspectral remote-sensing reflectance. Applied Optics 33(24): 5721-5732.

Lee, S.Y., Dunn, R. J. K., Young, R. A, Connolly, R., Dale, P. E., Dehayr, R., C. J, Lemckert. Mckinnon, J., Powell, S., Teasdale, P. R., and Welsh, D. T., 2006. Impact of urbanization on coastal wetland structure and function. Austral Ecology 31(2).

Leopold, L. B., 1968. Hydrology for urban planning, a guidebook on the hydrologic effects of urban land use. U.S Geological Survey Circular 554, Washington, D.C: U.S Department of the Interior.

Maitra, S. and Yan, J., 2008. Principal component analysis and partial least squares: two dimension reduction techniques for regression. Casualty Actuarial Society, Discussion Paper Program.

Mathews, T. D., Stapor, F. W., Richter, C. R., Miglarese, J. V., McKenzie, M. D., and Barclay, L. A., 1980. Ecological Characterization of the Sea Island Coastal Region of South Carolina and Georgia, Volume I: Physical Characterization Area.

McClain, C. R., 2009. A decade of satellite ocean color observations. Annual Review of Marine Science 1:19-42.

McIntyre, M. P., Eilers, H. P., and Mairs, J. W., 1991. Physical Geography. Wiley and Sons, New York, NY.

Miller, R. L., Belz, M., Del Castillo, C., and Trzaska, R., 2002. Determining CDOM absorption spectra in diverse coastal environments using multiple path length, liquid core waveguide system. Continental Shelf Research 22:1301-1310.

Milligan, T. G., Kineke, G. C., Blake, A. C, Alexander, C. R, and Hill, P. S., 2001. Flocculation and sedimentation in the ACE Basin, South Carolina. Estuaries 24(5):734-744.

Mobley, C., 1999. Estimation of the remote-sensing reflectance from above-surface measurements. Applied Optics 38(36):7442-7455.

Moses, W. J., Gitelson, A. A., Berdnikov, S., Saprygin, V., and Povazhnyi, V., 2012. Operational MERIS-based NIR-red algorithms for estimating chlorophyll-a concentrations in coastal waters-The Azov Sea case study. Remote Sensing of the Environment 121:118-124.

Noble, P. A., Tymowski, R. G., Fletcher, M., Morris, J. T., and Lewitus, A. J., 2003. Contrasting patterns of phytoplankton pigment composition in two salt marsh estuaries in Southeastern United States. Applied Environmental Microbiology 69: 4129-4143.

Nwaodua, E. C., Ortiz, J. D., and Griffith, E. M., 2014. Diffuse spectral reflectance of surficial sediments indicates sedimentary environments on the shelves of the Bering Sea and western Arctic. Marine Geology 355: 218-233.

Ortiz, J. D., Witter, D. L., Ali, K. A., Fela, N., Duff, M., and Mills, L., 2013. Evaluating multiple colour-producing agents in Case II waters from Lake Erie. International Journal of Remote Sensing 34(24): 8854-8880.

Robertson, A. L., Tedesco, L. L., Wilson, J., and Soyeux, E., 2009. Using partial least squares (PLS) method for estimating cyanobacterial pigments in eutrophic inland 
waters. In W. G. Jackson (eds.), Remote Sensing and Modeling of Ecosystems for Sustainability 7454(8).

Rodriguez-Guzman, V. and Gilbes-Santaella, F., 2009. Using MODIS $250 \mathrm{~m}$ imagery to estimate total suspended sediment in a tropical open bay. International Journal of Systems Applications, Engineering \& Development 3(1): 36-44.

Romero-Vivas, E., Von Borstel, F. D,. Perez-Estrada, C., Torres-Ariño, D., Villa-Medina, F. J., and Gutierrez J., 2015. On water remote monitoring robotic system for estimating patch coverage of Anabaena sp. filaments in shallow water. Environmental Science: Processes and Impacts. doi:10.1039/C5EM00097A.

Ryan, K. and Ali, K. A., 2016. Application of a partial least squares regression model to retrieve chlorophyll- $a$ concentrations in coastal waters using hyper-spectral data. Ocean Science Journal 51(2):209-221.

Sathyendranath, S. and Platt, T., 1997. Analytical model of ocean color. Applied Optics 36(12): 2620-2629.

Schalles, J. F., 2006. Optical remote sensing techniques to estimate phytoplankton chlorophyll-a concentrations in coastal waters with varying suspended matter and CDOM concentrations. Ch. 3 In, Richardson, L. and E. LeDrew (eds.), Remote Sensing of Aquatic Coastal Ecosystem Processes: Science and Management Applications. Springer:27-79.

Soller, D. R and Mills, H. H., 1991. Surficial geology and geomorphology. In: J. W Horton and V.A Zullo (eds.), The Geology of the Carolinas: Carolina Geological Society Fiftieth Anniversary Volume. University of Tennessee Press, Knoxville, TN.

SCWRC, 1972. ACE framework study: Ashley-CombaheeEdisto River Basin. South Carolina Water Resources Commission, Columbia, SC.

Stapor, F. W., 1984. Sand transport at Edisto Beach, Colleton County, South Carolina. South Carolina Marine Resources Center. Technical Report No.60: 8.

Stumpf, R. P., 1988. Sediment transport in Chesapeake Bay during floods: Analysis using satellite surface observations. Journal of Coastal Research 4:1-15.

United States Environmental Protection Agency (USEPA), 2012. Oceans, Coasts and Estuaries. Retrieved 2015, from United States Environmental Protection Agency http:// www3.epa.gov/region9/water/oce/coastalwaters.html. Van Dolah, R. F., Jutte, P. C., Riekerk, G. H. M., Levisen, M. V., Crowe, S. E., Lewitus, A. J., Chestnut, D. E., McDermott, W., Bearden, D., and Fulton M. H., 2004. The condition of South Carolina's estuarine and coastal habitats during 2001-2002: South Carolina Marine Resources Division, Charleston, SC. Technical Report No.100: 70.

Vasilkov, A., and Kopelevich, O.,1982. Reasons for the appearance of the maximum near $700 \mathrm{~nm}$ in the radiance spectrum emitted by the ocean layer. Oceanology 22 (6): 697-701.

Witter, D. L., J. D. Ortiz, S. Palm, R. T. Heath, and Budd, J. W., 2009. Assessing the application of SeaWiFS ocean color algorithms to Lake Erie. Journal of Great Lakes Research 35: 361-370.

Yacobi Y. Z., Moses, M. J., Kaganovsky. S., Sulimani, B., Leavitt, B. C., and Gitelson, A. A., 2011. NIR-red reflectance-based algorithms for chlorophyll- $a$ estimation in mesotrophic inland and coastal waters: Lake Kinneret case study. Water Resources 45:2428-2436. 